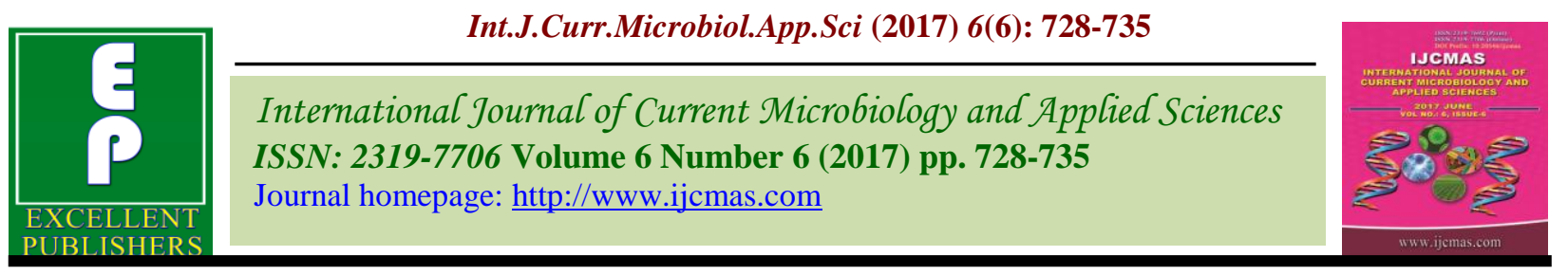

Original Research Article

https://doi.org/10.20546/ijcmas.2017.606.086

\title{
An Assessment of Temperate Rice (Oryza sativa L.) Germplasm for Grain Quality Attributes
}

\author{
Arpit Gaur ${ }^{1}$, Ghulam Ahmad Parray ${ }^{2 *}$, Asif B. Shikari ${ }^{3}$, Shabir Hussain Wani ${ }^{1}$, \\ Ashok Kumar Malav ${ }^{4}$, S. Najeeb ${ }^{2}$ and M. Ashraf Bhat ${ }^{1}$ \\ ${ }^{1}$ Division of Genetics and Plant Breeding, FoA-Wadura, SKUAST-Kashmir, \\ J\&K (190121), India \\ ${ }^{2}$ Mountain Research Centre for Field Crops, SKUAST-Kashmir, Khudwani, \\ J\&K (192101), India \\ ${ }^{3}$ Center for Plant Biotechnology, FoH, SKUAST-Kashmir, Shalimar, J\&K (190025), India \\ ${ }^{4}$ Department of Genetics and Plant Breeding, CoA, MPUAT, Udaipur, \\ Rajasthan (313001), India \\ *Corresponding author
}

\begin{tabular}{|c|c|}
\hline & A B S T R A C T \\
\hline & A total of 112 elite genotypes of temperate rice (Oryza sativa L.) were evaluated \\
\hline & and characterized for some grain quality parameters [KLBC, KLAC, KBBC, \\
\hline $\begin{array}{l}\text { Temperate rice, } \\
\text { Grain Quality, }\end{array}$ & investigated traits showed a wide range of variability. In the present experimental \\
\hline Aroma, & plant material medium sized $(66.96 \%)$ and bold shaped $(50.00 \%)$ grains, low AAC \\
\hline $\begin{array}{l}\text { Correlation and } \\
\text { PCA. }\end{array}$ & $\begin{array}{l}(79.65 \%) \text {, soft GC }(56.03 \%) \text {, high ASV }(47.32 \%) \text { and low GT }(47.32 \%) \text { were } \\
\text { found to be prevalent. Aroma was reported in seven genotypes namely Black Rice, }\end{array}$ \\
\hline Article Info & Muskbudji, Pusa 1509 and Pusa Sugandha 3. Four out of these seven genotypes \\
\hline $\begin{array}{l}\text { Accepted: } \\
\text { 14 May } 2017 \\
\text { Available Online: } \\
\text { 10 June } 2017\end{array}$ & $\begin{array}{l}\text { LBR showed a significantly positive correlation with KLBC, KLAC and Amylose } \\
\text { content. Further, the principle component analysis (PCA) revealed the existence of } \\
\text { substantial level of variability due to investigated traits. }\end{array}$ \\
\hline
\end{tabular}

\section{Introduction}

The grain quality of rice (Oryza sativa L.) is one of the most important attribute of rice crop. Grain quality is a multifaceted trait and plays a foremost role in dictating the consumers' choice and marketability (Juliano, 2003).Consumers' acceptability towards grain quality varies largely with the regions and ethnic groups (Unnevehr et al., 1985). Thus, definition of a good quality rice grain varies with the regions and ethnic groups. Shape, size, cooking and eating quality and aroma are the major grain quality attributes that are considered by consumer(s), invariably.

The size of rice grain is defined by its kernel length before cooking (KLBC) which further helps in categorizing the rice varieties in short ( $\leq 5.50 \mathrm{~mm})$, medium (5.51-6.60 mm), long 
$(6.61-7.50 \mathrm{~mm})$ and extra-long $(>7.50 \mathrm{~mm})$ grains. The grain shape is a complex trait which is defined with a ratio of kernel length before cooking (KLBC) and kernel breadth before cooking (KBBC), commonly known as the length to breadth ratio (LBR). On the basis of LBR a grain is defined as round ( $\leq$ 1.0), bold (1.1-2.0), medium (2.1-3.0) and slender $(>3.0)$. Further, three other parameters viz., kernel length after cooking (KLAC), kernel breadth after cooking (KBAC) and kernel expansion ratio (KER) gives a prediction of grain appearance after cooking. In numerous studies significant associations between size \& shape of rice grain and yield contributing traits have been reported; thus, these attributes also have great importance in breeding programs for yield improvement (Tan et al., 2000; Adair et al., 1966).

Starch is a major factor that affects cooking and eating quality of rice grain. This is largely associated with apparent amylose content (AAC), gel consistency (GC), alkali spreading value (ASV) and gelatinization temperature (GT).AAC is a major attribute that decides the behavior and firmness of a rice grain after cooking. On the basis of AAC rice variety may be classified under four distinguish classes viz., waxy (0-2\%), vary low (3-9\%), low (10-19\%), intermediate (20-25\%) and high amylose content (>26\%) (Kumar and Khush, 1986). Waxy rice is highly sticky, firm and do not expand in volume on cooking and are vary less preferable due to their nonexpanding nature and high stickiness. In contrast to waxy rice, high amylose content rice show high volume expansion and a high degree of flakiness, cooks dry, less tender and become hard upon cooling. In contrast to waxy and high amylose content, intermediate rice varieties are dominantly preferable as these rice cook moist, tender with good expansion and do not hard upon cooling (Kumar and Khush, 1986). Another important trait namely gel consistency (GC) is an index for determining the cooked rice texture. On the basis of $\mathrm{GC}$ a rice genotype may be classified as hard $(>40 \mathrm{~mm})$, medium (41 to $60 \mathrm{~mm}$ ) or soft (>61 mm). However, there are different suggestions for the correlation between amylose content and gel consistency but varieties having same amylose content may differ in tenderness; therefore, the cooked rice may be differentiated by the gel consistency test (Cagampang et al.,1973). In general rice varieties with intermediate amylose and soft gel, consistency is preferred by consumers (Tyagi et al., 2010).

The alkali spreading value (ASV) of milled rice grains in a weak base is simple measure to estimate gelatinization temperature (GT) and negatively correlated i.e. rice with low GT disintegrates completely, the one with intermediate GT are slow in disintegration while those with high GT remains unaffected. GT is a physical property of rice amylopectin that decides the cooking time of milled rice grains. The GT has been classified as low (55 to $\left.69^{\circ} \mathrm{C}\right)$, intermediate $\left(70\right.$ to $\left.74^{\circ} \mathrm{C}\right)$ and high $\left(>74^{\circ} \mathrm{C}\right)$ (Little et al., 1958).

Apart from physical appearance and cooking and eating quality, aroma of rice grain is another quality attributes which directly affect the choice of end consumers and marketability of rice, as consumers pay a premium price for scented rice in international market. A number of volatile and semi-volatile compounds have been identified by the phyto-chemists in various scented varieties of rice (Yang et al., 2008; Widjaja et al., 1996); however, the 2-Acetyl1-pyrroline (2AP) is the only recognized volatile compound that had been found significantly associated with characteristic pop-corn like aroma in most of the scented varieties of rice (Buttery et al., 1983).

Thus, in past few decades the trend of keeping rice grain quality improvement as a major objective in every rice improvement program has rapidly increased among the rice breeders. 
Improving the rice grain quality shall involve the screening of the available germ plasm for above mentioned traits. Thus accurate assessment of quality traits can be invaluable in crop breeding for diverse applications including introgression of desirable genes from diverse germ plasm into the available genetic base and for widening the narrow genetic base of the developed varieties (Roy and Sharma, 2014).

Thus, the present investigation was intended to characterize local landraces of Kashmir valley and some other elite genotypes of temperate rice maintained at the Mountain Research Centre for Field Crop-Khudwani, SKUAST-Kashmir, India (MRCFCKhudwani) for grain quality traits.

\section{Materials and Methods}

\section{Experimental plant material}

A total of 112 elite genotypes of temperate rice germplasm were procured from the germplasm repository of regional research centre of SKUAST-Kashmir, Jammu and Kashmir (India) namely MRCFC-Khudwani. All these genotypes were raised in Augmented Block Design under natural conditions following prescribed agronomical practices.

\section{Evaluation of rice grain quality parameters}

In the present investigation emphasize was given to the evaluation and characterization of the experimental plant material for their grain quality by following SES (2000). In the physical parameters KLBC (mm), KLAC $(\mathrm{mm}), \mathrm{KBBC}(\mathrm{mm}), \mathrm{KBAC}(\mathrm{mm}), \mathrm{LBR}$ and KER were considered. For the assessment of cooking and eating quality AAC (\%), GC (mm) and GT by means of ASV (both on a numerical scale from 1 to 7$)$ were evaluatedfollowingthe standard protocols described and published by Juliano et al., (1971); Cagampang et al.,(1973); Little et al., (1958), respectively. The presence of aroma was detected as per the simple laboratorial technique developed by IRRI (1971).

\section{Statistical analysis, trait association studies and PCA}

The whole statistical analysis was performed using XLSTATC version 10 (Addinsoft, 40, rue Damrémont, 75018 Paris, France). For the trait association studies we used Pearsons correlation coefficient (r). Further, the PCA was performed on the basis of Pearson correlation matrix and the calculated eigenvalues and eigenvectors. The principle components were extracted until they accounted for more than $70 \%$ of the cumulative contribution of the eigenvalues.

\section{Results and Discussion}

\section{Physical quality of rice grains}

In this study, a wide range of KLBC, KLAC, KBBC, KBAC, LBR and KER were recorded in germ plasm (Table 1). Further, on pursuing Figure 1(a) and 1(b), one may clearly see the majority of genotypes possessed medium sized (i.e.5.51-6.60 mm KLBC) and bold (i.e.1.1-2.0 LBR) grains. Our these results are in accordance with Mir et al., (2013) who conducted a study on the physical evaluation of temperate rice which included varieties Jhelum, K-332, Koshar, Pusa-3, SKAU-345, SKAU-382 and SR-1. We also found these results in agreement with Palanivel et al., (2016) and Varnamkhasti et al., (2008) who recorded at par ranges for different physical quality attributes of rice grain.

\section{Cooking and eating quality of rice grains}

All the 112genotypes were evaluated for the AAC (\%), GC (mm), ASV (1-7) and GT $\left({ }^{\circ} \mathrm{C}\right)$. 
Table 1 supports the presence of a wide range of AAC, GC, ASV and GT in our germplasm. Figure 1(c) to 1(e), further clarifies that low AAC, soft GC, high ASV and low GT was prevalent in our experimental plant material. On the basis of these results and the recommendation of Cruz and Khush (2000) we may further predict that rice grains of most of the genotypes belonging to our experimental plant material will probably take more time in cooking, get sticky and become soft. These results are in agreement of Popluechai et al., (2012) who estimated different levels of amylose content in Thai rice varieties varying from 18 to $22 \%$. These results are also at par with Husaini et al., (2009) and Shikari et al., (2008) who conducted their studies in temperate rice of Jammu and Kashmir.

In a sensory test for aroma, seven elite genotypes (Black Rice, Muskbudji, Mehvan Green, Mushkandi-I, Kamad, Pusa 1509 and Pusa Sugandh 3) from our experimental material were possessing aroma. Four out of these seven aromatic genotypes viz., Black rice, Mushkbudji, Kamad, Pusa 1509 and Pusa Sugandha 3 had already been recognized in many previous studies (Husainiet al., 2009; Shikari et al., 2008); however, no previous evidence supporting our detection of aroma in two elite genotypes viz., Mehvan Green and Mushkandi, was found, even after a vast survey of literature. Interestingly, characteristic popcorn like aroma of 2AP with high intensity was recorded only in Mushkbudji, Pusa 1509 and PusaSugandha3 whereas, the other four aromatic genotypes were possessing fragrance of mild intensity and it was quite difficult to differentiate the characteristic 2AP aroma. We are not sure about the cause behind this; however, the most probable reason for this may be the environmental effect and/or the genetic background and/or the presence of some other volatile compound(s) (Jewle et al., 2011; Jezussek et al., 2002; Widjaja et al., 1996).

Table.1 Descriptive statistics of tested grain quality traits

\begin{tabular}{|c|c|c|c|c|c|c|}
\hline Statistic & Minimum & Maximum & Range & Mean & SEm & CV \\
\hline KLBC & 4.20 & 7.90 & 3.70 & 5.89 & 0.06 & 0.10 \\
\hline KLAC & 5.66 & 17.65 & 11.99 & 8.40 & 0.13 & 0.17 \\
\hline KBBC & 1.78 & 3.40 & 1.62 & 2.78 & 0.03 & 0.11 \\
\hline KBAC & 2.10 & 4.80 & 2.70 & 3.63 & 0.04 & 0.11 \\
\hline LBR & 1.40 & 4.44 & 3.04 & 2.15 & 0.04 & 0.19 \\
\hline KER & 1.13 & 2.23 & 1.10 & 1.43 & 0.02 & 0.13 \\
\hline GC & 26.33 & 150.00 & 123.67 & 71.90 & 2.94 & 0.43 \\
\hline ASV & 1.00 & 7.00 & 6.00 & 4.78 & 0.17 & 0.37 \\
\hline ACC & 3.09 & 25.90 & 22.81 & 14.18 & 0.40 & 0.30 \\
\hline Aroma & 0.00 & 3.00 & 3.00 & 0.15 & 0.06 & 3.86 \\
\hline
\end{tabular}


Table.2 Estimates of Pearson's correlation coefficient (r) tested for grain quality parameters

\begin{tabular}{|l|cccccccccc|}
\hline Variables & $K L B C$ & $K L A C$ & $K B B C$ & $K B A C$ & $L B R$ & $K E R$ & $G C$ & $A S V$ & $A C C$ & $A$ roma \\
\hline KLBC & $\mathbf{1}$ & $\mathbf{0 . 5 8 4}$ & -0.177 & $\mathbf{- 0 . 2 6 3}$ & $\mathbf{0 . 7 2 0}$ & -0.047 & -0.182 & 0.009 & 0.184 & $\mathbf{0 . 2 1 3}$ \\
KLAC & $\mathbf{0 . 5 8 4}$ & $\mathbf{1}$ & $\mathbf{- 0 . 4 7 5}$ & $\mathbf{- 0 . 3 4 8}$ & $\mathbf{0 . 7 6 7}$ & $\mathbf{0 . 7 7 3}$ & $\mathbf{- 0 . 2 0 7}$ & 0.093 & 0.165 & $\mathbf{0 . 5 5 0}$ \\
KBBC & -0.177 & $\mathbf{- 0 . 4 7 5}$ & $\mathbf{1}$ & $\mathbf{0 . 4 7 2}$ & $\mathbf{- 0 . 7 8 0}$ & $\mathbf{- 0 . 4 2 3}$ & 0.054 & 0.039 & -0.183 & $\mathbf{- 0 . 3 8 5}$ \\
KBAC & $\mathbf{- . 2 6 3}$ & $\mathbf{- 0 . 3 4 8}$ & $\mathbf{0 . 4 7 2}$ & $\mathbf{1}$ & $\mathbf{- 0 . 5 3 0}$ & -0.170 & -0.065 & 0.012 & -0.087 & $\mathbf{- 0 . 2 6 4}$ \\
LBR & $\mathbf{0 . 7 2 0}$ & $\mathbf{0 . 7 6 7}$ & $\mathbf{- 0 . 7 8 0}$ & $\mathbf{- 0 . 5 3 0}$ & $\mathbf{1}$ & $\mathbf{0 . 3 5 6}$ & -0.149 & 0.000 & $\mathbf{0 . 2 8 7}$ & $\mathbf{0 . 4 9 6}$ \\
KER & -0.047 & $\mathbf{0 . 7 7 3}$ & $\mathbf{- 0 . 4 2 3}$ & -0.170 & $\mathbf{0 . 3 5 6}$ & $\mathbf{1}$ & -0.127 & 0.121 & 0.019 & $\mathbf{0 . 4 6 1}$ \\
$G C$ & -0.182 & $\mathbf{- 0 . 2 0 7}$ & 0.054 & -0.065 & -0.149 & -0.127 & $\mathbf{1}$ & 0.112 & -0.099 & -0.059 \\
ASV & 0.009 & 0.093 & 0.039 & 0.012 & 0.000 & 0.121 & 0.112 & $\mathbf{1}$ & 0.003 & 0.077 \\
ACC & 0.184 & 0.165 & -0.183 & -0.087 & $\mathbf{0 . 2 8 7}$ & 0.019 & -0.099 & 0.003 & $\mathbf{1}$ & $\mathbf{0 . 2 1 6}$ \\
Aroma & $\mathbf{0 . 2 1 3}$ & $\mathbf{0 . 5 5 0}$ & $\mathbf{- 0 . 3 8 5}$ & $\mathbf{- 0 . 2 6 4}$ & $\mathbf{0 . 4 9 6}$ & $\mathbf{0 . 4 6 1}$ & -0.059 & 0.077 & $\mathbf{0 . 2 1 6}$ & $\mathbf{1}$ \\
\hline
\end{tabular}

Values in bold are different from 0 with a significance level alpha $=0.05$

Table.3 Estimates of eigenvectors and factor lodgings for grain quality

\begin{tabular}{|c|c|c|c|c|c|c|c|c|}
\hline & \multicolumn{2}{|c|}{ PC1 } & \multicolumn{2}{|c|}{ PC2 } & \multicolumn{2}{|c|}{ PC3 } & \multicolumn{2}{|c|}{ PC4 } \\
\hline & Eigenvectors & $\begin{array}{l}\text { Factor } \\
\text { Loading }\end{array}$ & Eigenvectors & $\begin{array}{l}\text { Factor } \\
\text { Loading }\end{array}$ & $\begin{array}{c}\text { Eigenvector } \\
\mathrm{s}\end{array}$ & $\begin{array}{l}\text { Factor } \\
\text { Loading }\end{array}$ & Eigenvectors & $\begin{array}{l}\text { Factor } \\
\text { Loading }\end{array}$ \\
\hline KLBC & 0.301 & 0.591 & -0.507 & -0.581 & -0.054 & -0.057 & 0.350 & 0.355 \\
\hline KLAC & 0.457 & 0.895 & 0.138 & 0.158 & -0.209 & -0.223 & 0.073 & 0.074 \\
\hline KBBC & -0.377 & -0.740 & -0.050 & -0.058 & -0.249 & -0.267 & 0.299 & 0.303 \\
\hline KBAC & -0.288 & -0.564 & 0.097 & 0.111 & -0.510 & -0.546 & 0.168 & 0.171 \\
\hline LBR & 0.476 & 0.933 & -0.214 & -0.245 & 0.115 & 0.123 & 0.026 & 0.026 \\
\hline KER & 0.314 & 0.615 & 0.573 & 0.657 & -0.253 & -0.270 & -0.169 & -0.171 \\
\hline $\mathrm{GC}$ & -0.103 & -0.202 & 0.229 & 0.262 & 0.734 & 0.786 & 0.145 & 0.147 \\
\hline ASV & 0.028 & 0.055 & 0.383 & 0.439 & 0.081 & 0.087 & 0.794 & 0.805 \\
\hline $\mathrm{ACC}$ & 0.158 & 0.311 & -0.289 & -0.332 & -0.075 & -0.081 & 0.269 & 0.273 \\
\hline Aroma & 0.337 & 0.662 & 0.235 & 0.270 & -0.057 & -0.061 & 0.038 & 0.038 \\
\hline Eigenvalue & \multicolumn{2}{|c|}{3.844} & \multicolumn{2}{|c|}{1.313} & \multicolumn{2}{|c|}{1.146} & \multicolumn{2}{|c|}{1.029} \\
\hline Variability (\%) & \multirow{2}{*}{\multicolumn{2}{|c|}{$\frac{38.441}{38.441}$}} & \multirow{2}{*}{\multicolumn{2}{|c|}{$\frac{13.134}{51.575}$}} & \multirow{2}{*}{\multicolumn{2}{|c|}{$\begin{array}{l}11.464 \\
63.039\end{array}$}} & \multicolumn{2}{|c|}{$\frac{10.289}{73238}$} \\
\hline Cumulative (\%) & & & & & & & 73.3 & \\
\hline
\end{tabular}

Fig.1 Relative frequency of various classes of (A) Grain size, (B) Grain Shape, (C) Alkali Spreading Value and Gelatinization Temperature, (D) Amylose Content,

(E) Gel Consistency and (F) Aroma
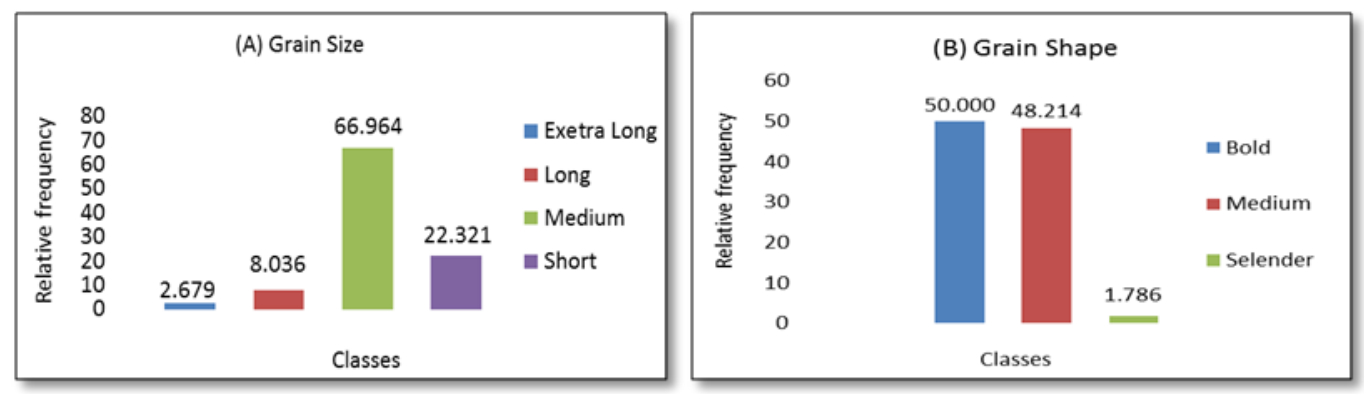

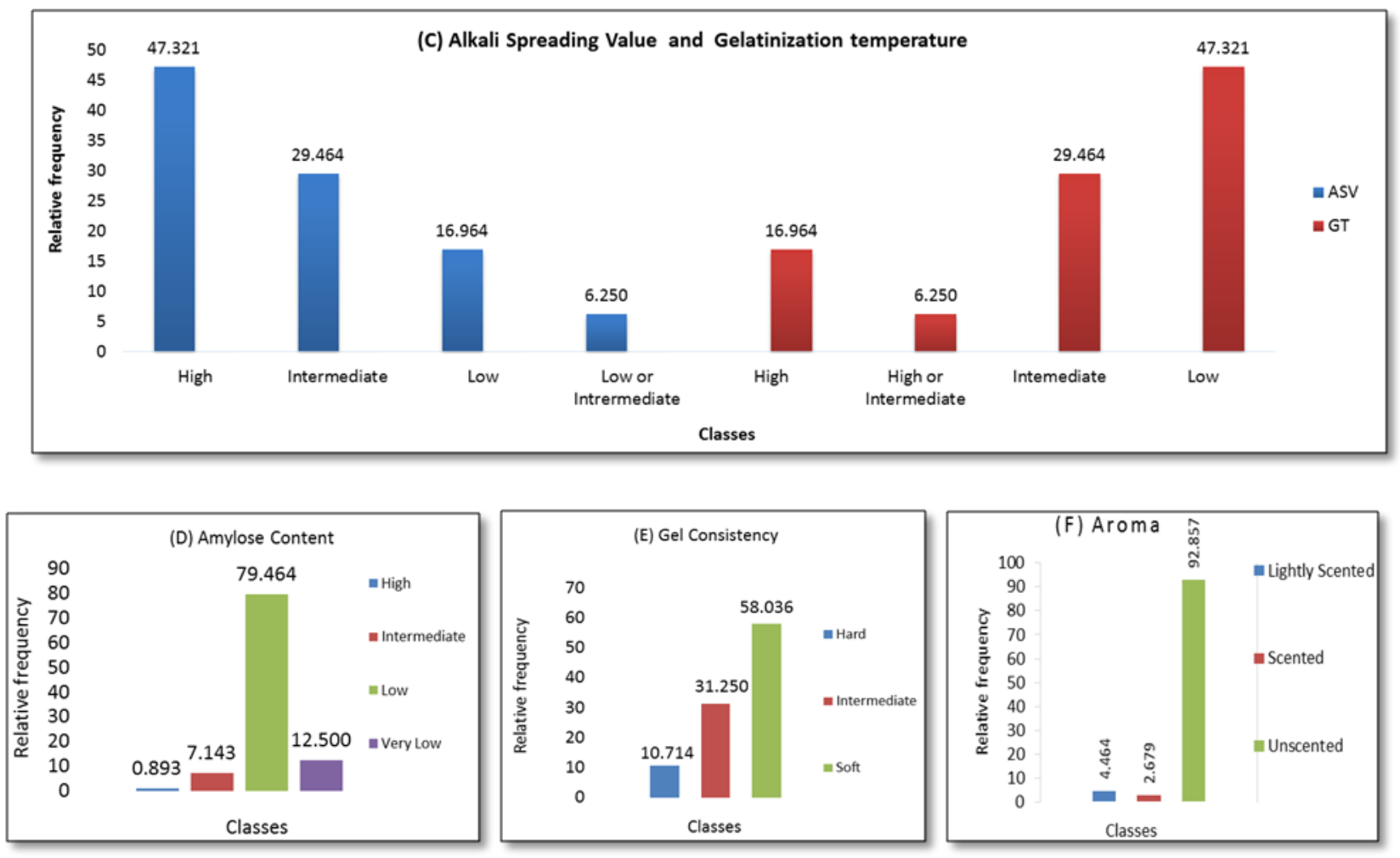

\section{Trait association and PCA}

The trait association studies help in direct and indirect selection during crop improvement programme(s). Table 2 gives a clear insight about the association between grain quality traits. In the present investigation we recorded a significantly positive association between KLBC, KLAC and LBR. These three traits were found to be negatively associated with $\mathrm{KBBC}$ and KBAC. These results are at par with the findings of Balakrishnan et al., (2013) and Khatun et al., (2003). Among cooking and eating quality traits, AAC showed a positive association with ASV (thus a negative correlation with GT) and significantly negative association with GC. Further, on establishing an inter-association study between physical traits and cooking and eating quality traits AAC showed significant positive association with KLBC, KLAC and LBR whereas, a significantly association with KBBC and KBAC. All these relationships were in conformity with Moulick et al.,
(2016), Eram et al., (2014), Bansal et al., (2006) and Chang and Li (1981).

The PCA is a measure that helps in estimating the part played by each component in producing the variations among the genotypes. The PCA revealed that the first four axes were largely accounted for the variations among the germplasm (Table 2). For $\mathrm{PC} 1$, the corresponding loadings were negative for $\mathrm{KBBC}$, KBAC and $\mathrm{GC}$ and positive for other traits (Table 3). For PC2, the loadings were negative for KLBC, KBBC, LBR and AAC. For PC3, the loadings were negative for most of the traits except for LBR, GC and ASV. For PC4, the loadings were almost positive except for KER (Table 2). This study has a support of the similar type of studies carried out by Hori et al., (2016) and Daiko et al., (2011).

The present investigation was concentrated on the characterization of some landraces of Kashmir valley and elite genotypes of 
temperate rice maintained at MRCFCKhudwani to provide information for improvement of valuable grain quality traits. A wide range of various grain quality traits was recorded. Hence, these genotypes may be used to exploit the genetic diversity and in biotechnological researches for further improvement of rice grain quality. Further, the three aromatic genotypes viz., Kamad, Mehvan Green and Mushkandi-I are needed to be revaluated for their aroma at molecular as well as biochemical level.

\section{Acknowledgement}

Authors are highly thankful to Department of Biotechnology (DBT Project No. DBT/AGII//935/2014) and AICRP-Rice for financial supports. Authors are also thankful to Associate Director Research, MRCFCKhudwani for providing invaluable experimental plant material.

\section{References}

Adair, C.R., Beachell, H.M., Jodon, N.E., Johnston, T.H., Thysell, J.R., Green, V.E., Webb, B.D. and Atkins, J.G. 1966. Rice breeding and testing methods in the US. In: US. Dept. of Agric. Rice in the US: Varieties and production. USDA Agri. Res. Sew. Handbook. 289: 19-64.

Addinsoft, S.A.R.L. 2010. XLSTAT-software, version 10. Addinsoft, Paris, France.

Balakrishnan, D., Robin, S. and Joel, A.J. 2013. Waxy gene polymorphism and its association with grain quality traits in selected landraces of rice. Oryza-An Int. J. Rice, 50(3): 214221.

Bansal, U.K., Kaur, H. and Saini, R.G. 2006. Donors for quality characteristics in aromatic rice. Oryza-An Int. J. Rice, 43(3): 197.

Buttery, R.G., Ling, L.C., Juliano, B.O. and Tumbaugh, J. 1983. Cooked rice aroma and 2-acetyl-1-pyrroline. J. Agric. Food Chem., 31: 823-826.

Cagampang, G.B., Perez, C.M. and Juliano, B.O. 1973. A gel consistency test for eating quality of rice. J. Sci. Food Agric., 24: 15891594.

Chang, W.L. and Li, W.Y. 1981. Inheritance of amylose content and gel consistency in rice. Bot. Bull. Acad. Sin, 22: 35-47.

Cruz, N.D. and Khush, G.S. 2000. Rice grain quality evaluation procedures. In: R.K Singh, U.S. Singh and G.S. Khush (Eds). Aromatic rices. Oxford and IBH Publishing Co Pvt. Ltd, New Delhi, p. 15-28.

Diako, C., Manful, J.T., Johnson, P.N.T., SakyiDawson, E., Bediako-Amoa, B. and Saalia, F.K. 2011. Physicochemical characterization of four commercial rice varieties in Ghana. Adv. J. Food Sci. Technol., 3(3): 196-202.

Eram, S., Singh, A.K., Singh, A., Singh, N.K. and Singh, P.K. 2014. Physicochemical characterization and organoleptic analysis in rice cultivars. India J. Agric. Res., 48(6): 437-445.

Hori, K., Suzuki, K., Iijima, K. and Ebana, K. 2016. Variation in cooking and eating quality traits in Japanese rice germplasm accessions. Breeding Sci., 66(2): 309-318.

Husaini, A.M., Parray, G.A., Rather, A.G. and Sanghera, G.S. 2009. Performance of elite basmati rice varieties of subtropical India under temperate valley conditions of Kashmir. Int. Rice Res. Notes, p. 4117-4185.

International Rice Research Institute. 1971. Annual Report for 1970. Los Baños, Laguna, Philippines. Pp. 265.

Jewel, Z.A., Patwary, A.K., Maniruzzaman, S., Barua, R., Begum, S.N. 2011. Physicochemical and Genetic Analysis of Aromatic Rice (Oryza sativa L) Germplasm. The Agriculturists, 9: 82-88.

Jezussek, M., Juliano, B.O., Schieberle, P. 2002. Comparison of key aroma compounds in cooked brown rice varieties based on aroma extract dilution analyses. J. Agric. Food Chem., 50: 1101-1105.

Juliano, B.O. 1971. A Simplified Assay for Milled-Rice Amylose. Cereal Sci. Today, 16: 334-360.

Juliano, B.O. 2003. Rice Chemistry and Quality. Phil Rice.

Khatun, M.M., Ali, M.H. and Cruz, Q.D. 2003. Correlation studies on grain physicochemical characteristics of aromatic rice. Pak. J. Biol. Sci., 6: 511-513. 
Kumar, I. and Khush, G.S. 1986. Gene dosage effect of amylose content in rice endosperm. Japanese J. Genet., 61: 559-568.

Little, R.R., Hilder. G.B. and Dawson, E.H. 1958. Differential effect of dilute alkali on 25 varieties of milled white rice. Cereal Chem., 35: 111-126.

Mir, S.A., Bosco, S.J.D. and Sunooj, K.V. 2013. Evaluation of physical properties of rice cultivars grown in the temperate region of India. Int. Food Res. J., 20(4): 1521-1527.

Moulick, D., Ghosh, D. and Santra, S.C. 2016. An assessment of some physicochemical properties and cooking characteristics of milled rice and associated health risk in two rice varieties of arsenic contaminated areas of West Bengal, India. Int. J. Res. Agric. Food Sci., 6(2): 44-55.

Palanivel, H., Puran, K., Kumar, R., Kumar, S. and Nath, P. 2016. Study on Physicochemical Properties of Rice Varieties in Fiji. J. Agric. Sci., 8(4): 101.

Popluechai, S., Laosat, N., Sasanatayart, R. and Kespechara, K. 2012 Appear amylose content and single nucleotide polymophisms (SNPs) of wx genes in some thai rice (Oryza sativaL. varindica). In: 1st Mae FahLaung University International Conference, Chiang Rai, Thailand.

Roy, S.C. and Sharma, B.D. 2014. Assessment of genetic diversity in rice [Oryza sativa L.] germplasm based on agro-morphology traits and zinc-iron content for crop improvement. Physiol. Mol. Biol., 20(2): 209-224.
Shikari, A.B., Hussain, S.A., Parray, G.A., Rather, A.G. and Wani, S.Q. 2008. Physico-chemical and Cooking properties of non-basmati temperate rice (Oryza sativa L.). Crop Improvement, 25(2): 109-114.

Standard evaluation system for rice (SES). 2002. International Rice Research Institute, Manila, Philippines. Pp. 30-32.

Tan, Y.F., Xing, Y.Z., Li, J.X., Yu, S.B., Xu, C.G. and Zhang, Q. 2000. Genetic bases of appearance quality of rice grains in Shanyou 63, an elite rice hybrid. Theor. Appl. Genet., 101: 823-829.

Tyagi, J.P., Singh, T. and Singh, V.P. 2010. Genetic analysis of combining ability for quality characters in Basmati rice. ORYZAAn Int. J. Rice, 47(2): 96-99.

Unnevehr, L.J., Juliano, B.O., Perez, C.M. and Marciano, E. 1985. Consumer demand for rice grain quality in Thailand, Indonesia, and the Philippines. IRRI Res. Paper Series, 116: 20.

Varnamkhasti, M.G., Mobli, H., Jafari, A., Keyhani, A.R., Soltanabadi, M.H., Rafiee, S. and Kheiralipour, K. 2008. Some physical properties of rough rice (Oryza sativaL.) grain. J. Cereal Sci., 47(3): 496-501.

Widjaja, R., Craske, J.D. and Wootton, M. 1996. Comparative studies on volatile components of non-fragrant and fragrant rices. J. Sci. Food Agric., 70: 151-161.

Yang, D.S., Shewfelt, R.L., Lee, K.S., Kays, S.J. 2008. Comparison of odor-active compounds from six distinctly different rice flavor types. J. Agric. Food Chem., 56: 2780-2787.

\section{How to cite this article:}

Arpit Gaur, Ghulam Ahmad Parray, Asif B. Shikari, Shabir Hussain Wani, Ashok Kumar Malav, S. Najeeb and Ashraf Bhat, M. 2017. An Assessment of Temperate Rice (Oryza sativa L.) Germplasm for Grain Quality Attributes. Int.J.Curr.Microbiol.App.Sci. 6(6): 728-735. doi: https://doi.org/10.20546/ijcmas.2017.606.086 